\title{
Bogotá arte urbano o graffiti. Entre la ilegalidad y la forma artística de expresión
}

\section{Bogota urban art o graffiti. Between illegality and artistic form of expression}

\author{
M. Martha Gama-Castro \\ Universidad Militar Nueva Granada. Colombia \\ maria.gama@unimilitar.edu.co \\ FREDDY LEÓN-REYES \\ Universidad Militar Nueva Granada. Colombia \\ freddy.leon@unimilitar.edu.co
}

Recibido: 7 de septiembre de 2015

Aprobado: 18 de diciembte de 2015

\begin{abstract}
Resumen
La investigación sobre el graffiti relacionado con el arte urbano, el diseño y la comunicación visual, la cultura social y política en la ciudad de Bogotá, son temas que concentran esta investigación. Opiniones y entrevistas fueron revelando la influencia sobre la comunidad, la sociedad civil, la política, y el enfrentamiento radical con la leyes, su clasificación y su exigencia según el estrato social han hecho de los espacios públicos de Bogotá una ciudad con paredes hablantes. Aunque no es tomado como algo malo, -para algunos- vandalismo para otros, despierta en muchos, opiniones diversas y sobre todo una subestimada valoración de los artistas hacia una expresión liberal y democrática de un sistema que los aleja de cualquier exhibición del arte tradicional.
\end{abstract}

Palabras clave: graffitti, expresión, ilegalidad, sociedad, arte callejero.

Gama-Castro, M.M., León-Reyes, F. (2016): Bogotá arte urbano o graffiti. Entre la ilegalidad y la forma artística de expresión. Arte, Individuo y Sociedad, 28(2) 355-369

\begin{abstract}
The research related to urban graffiti art, design and visual communication, social culture and politics in the city of Bogota, are issues that this research focus. Reviews and interviews were revealing the influence on the community, civil society, politics and the radical confrontation with the law, their classification and their demand different social strata have made public spaces in Bogota a city with walls speakers. Although it is not taken as a bad thing, -for some- vandalism to others, awakens in many different opinions and above all understated assessment of the artists towards a liberal and democratic expression of a system that moves away from any display of traditional art. Keywords: graffitti, expression, society, illegality, street art.
\end{abstract}


Sumario: 1. Introducción, 2. La crítica al aire, 3. Arte y cultura o Ilegalidad y vandalismo, 3.1. Perspectiva social, 3.2. Análisis antropológico, 3.3. Arte callejero-graffiti, 4. El ordenamiento territorial, 4.1. Aspectos generales de la ley, 5. Conclusiones. Referencias.

Este artículo recoge resultados de la investigación "Resignificación del Street art o (in) cultura ciudadana. Bogotá un gran lienzo para la anamorfosis". INV. ING 1813, financiada por la Universidad Militar Nueva Granada.

\section{Introducción}

Sobre el graffiti en Bogotá Castro, S (2012), dice:

Es un hecho social que está asociado con la acción directa de generar una marca en la calle, esta acción puede ser una huella particular que representan una o varias personas, es una subcultura y un estilo de vida para quienes se dedican a él, que ven en esto un medio para buscar emociones y rebelarse de manera sutil pero a la vez contundente ante una autoridad impuesta. Desde el 2007, en Bogotá, se empieza a presentar un incremento en el interés por el tema del graffiti, desde entonces muchos graffiteros o artistas callejeros han vinculado sus oficios con formas comerciales de producción transformándolo en un medio para diferentes propósitos. (p. 25).

La práctica de la comunicación gráfico-visual ocurrió incluso antes que la verbal (Berger, 2002), cuando los hombres primitivos se vieron en la necesidad de dejar vigencia de su existencia en las paredes de las cavernas, precisamente, la comunicación gráfica informal, anónima, fugaz o espontánea (por llamarle de algún modo al ejercicio que nos ocupa) ha persistido hasta nuestros días en que ha logrado evolucionar tanto en calidad como en cantidad; por ejemplo, toda imagen publicitaria es comunicación retórica y su creatividad ha de servir para este fin. De allí que la intención comunicativa del anuncio exterior sea persuadir a través de argumentos emocionales tanto o más que con los cognoscitivos, voluntad que persigue con la selección y combinación de signos visuales para la construcción de sus argumentos (Vega, B., 2012. P15), como muestra a través de numerosos trabajos de investigación se ha concluido que la comunicación es un proceso de carácter social que comprende todos los actos mediante los cuales los seres vivos establecemos contacto con nuestros semejantes para transmitir o intercambiar información. (Vega, B., 2012. P67).

Muchas expresiones pictóricas en la ciudad de Bogotá, se presentan amalgamadas bajo el nombre graffiti, algunas de estas expresiones se pueden elevar al término de prácticas culturales, porque cuentan con una organización, una historia y unos representantes claros; esto ha permitido a los investigadores crear una clasificación estética del graffiti y situarlo dentro de categorías como: i) el graffiti de consigna o graffiti fanático barrista (de barrio), ii) el writting y iii) el arte urbano (Castro, S., 2012. P26).

Así pues para la ciudad de Bogotá se establecieron unas reglas en el plan de ordenamiento territorial sobre el libre tránsito en el espacio público. Desde el punto 
de vista funcional se dan unas directrices para la localización de las expresiones. La única regla que existe para direccionar el arte en el espacio público es que no obstruya la circulación. Creo que entender una reglamentación del graffiti es muy difícil. (Castro, S., 2012). Por otra parte, la mayoría de formas de pintura en las calles es proveniente de los artistas urbanos y los escritores de graffiti de tiempo completo, que dedican gran parte de su vida a intervenir el espacio público de la ciudad con sus nombres, sus barrios, sus barras, letreros gigantes, murales de gran formato hechos a mano alzada o con plantillas, pinturas de personajes anónimos o celebridades de la cultura popular del país (fig 1), así como plantillas directas puestas que visibilizan un lugar o una situación específica (Castro, S., 2012, p.41), precisamente algunos tipos de graffiti están enfocados en la difusión de mensajes personales o de denuncia social, otros aparecen para definir límites territoriales de grupos sociales en la ciudad, mientras que otros están en un diálogo continuo con el arte. Dado lo anterior la investigación plantea los siguientes interrogantes para su desarrollo: ¿Cómo puede el graffiti comunicar los pensamientos de su creador? ¿Qué significado tiene el graffiti como labor profesional?

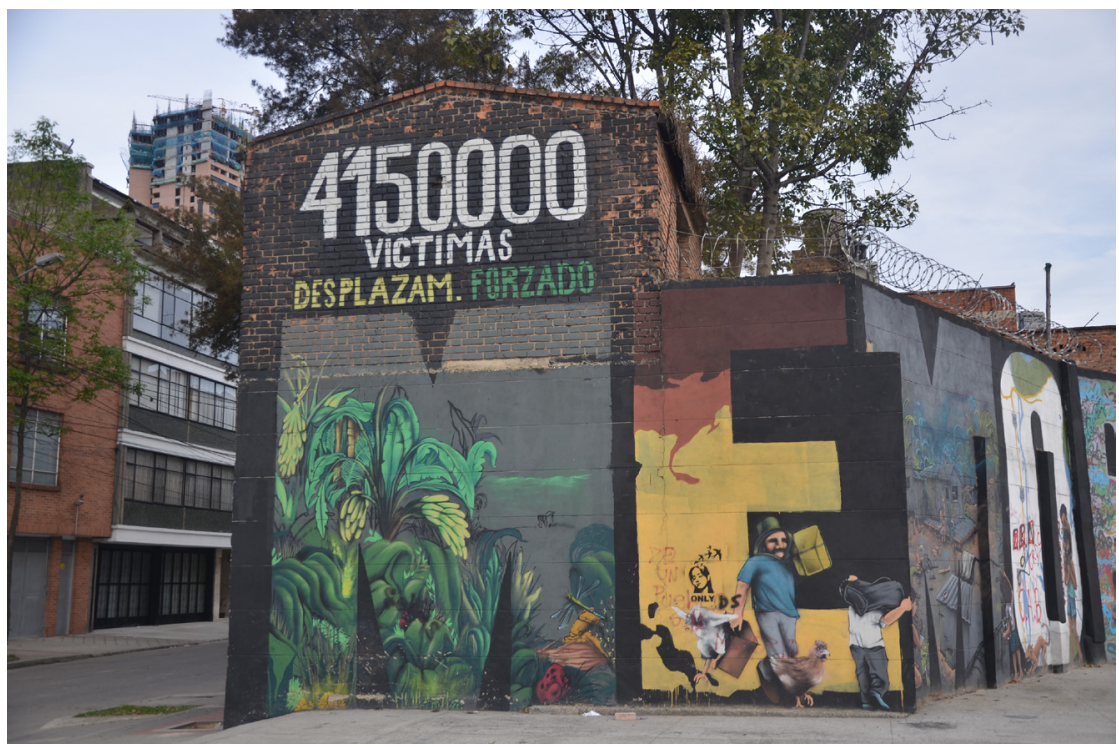

Figura 1. La posición frente al conflicto armado que por más de 50 años ha vivido el país es frecuente tema para los artistas callejeros. La imagen revela el nivel de población que se ha visto forzada a abandonar sus tierras y desplazarse a la ciudad (fotografía del autor).

En esta ciudad son varias las inconformidades que expresan las personas que la habitan; muchos son movimientos obreros-sindicatos y juveniles-estudiantiles que con marchas y sus arengas reclaman un estado más equitativo y por otro lado y aunque están en el aire rondando, son pocos los que deciden hacerlas visibles. Dentro de ese reducido grupo están los artistas urbanos, que narran en las paredes de los altos edificios historias de amor, sucesos del conflicto armado, costumbres, crítica social, posturas políticas; que decidieron, a través del arte, hacer memoria y ahora son pocas 
las calles que no tienen un dibujo, una historia, un pensamiento, una postura, una idea. Sí, Bogotá ahora es la ciudad del graffiti. Hasta 2011, esta actividad era ilegal, pero después de la muerte del joven graffitero Diego Felipe Becerra por el disparo de un policía cuando se encontraba pintando en la localidad de Suba, las autoridades decidieron apostar por una nueva norma que no prohibiera la actividad, pero que la regulara. En 2013 se firmó el decreto 75 "Por el cual se promueve la práctica artística y responsable del grafiti en la ciudad y se dictan otras disposiciones". (http:// www.elespectador.com/noticias/bogota/un-museo-de-arte-urbano-cielo-abiertoarticulo-553089).

La Fundación Arteria, en convenio con la Gerencia de Artes Plásticas y Visuales contrató un diagnóstico sobre el estado del sector graffiti en Bogotá y en junio de 2012, se creó la Mesa Distrital de Graffiti, para discutir sobre reglamentos, temas y tipos de graffitis, $y$ proponer políticas que establezcan el buen uso del espacio público, cuyo objeto es identificar de manera diversa y amplía agentes productores, formas de representación y organización, y los agentes directos que hacen parte del desarrollo en la ciudad para indagar sobre sus necesidades y proponer estrategias para el fortalecimiento y entendimiento de esta práctica. (Castro, S., Vásquez, R., Fajardo, E., Mojica, S., Arbeláez, V., García, S. (2012). Diagnóstico Graffiti Bogotá 2012. Graffiti Bogotá 2012.)

De acuerdo con lo anterior, sigue la comunidad de la ciudad de Bogotá, viendo ésta práctica como un acto vandálico y a quienes los hacen como verdaderos criminales y canallas.

\section{La crítica al aire}

Las grandes ciudades pasaron de la letra a la imagen, ya no es simplemente la descripción apológica hacia algo, o la crítica, o la sátira que refleja el descontento de una sociedad que se resigna a un sistema pero que encuentra en los medios de expresión clandestinos la forma de gritar al mundo su posición.

El arte callejero, ha viabilizado una nueva forma de comunicación convirtiendo las paredes de las calles en verdaderos lienzos, para artistas en su mayoría empíricos. Dice Louis Bou (2010) sobre el Street art.

El street art convierte las calles de las grandes ciudades en exposiciones de arte al aire libre, produciendo un impacto socio-cultural que permite una comunicación más universal, pues las personas que nunca antes habían pisado un museo quedan absorbidas por esta macro-producción artística. (p.11).

El contacto con una ciudad que cambia su aspecto cotidiano produce emociones, ya no es una visión de concreto que aturde sino una exposición de arte que embellece y adorna su recorrido (fig 2). Se ha pasado del graffiti a la imagen, al color y a las formas. 


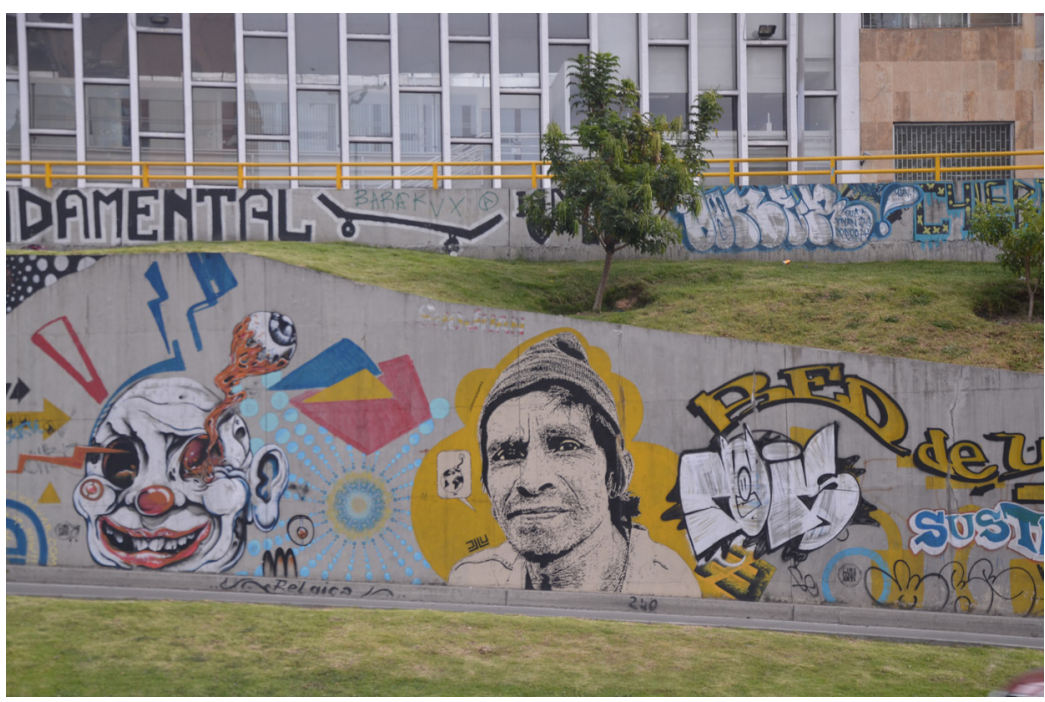

Figura 2. Calle 26. Centro de Bogotá. Invadido en su recorrido que atraviesa la ciudad de oriente a occidente por llamativos graffitis y pinturas de artistas callejeros. (fotografía del autor).

Aunque no se puede separar el arte urbano de la práctica política, del debate y de la crítica; al artista callejero no le interesa intervenir en política, según su opinión es su desarrollo personal, es su gusto y estilo, es su forma de vida tal como lo dice Uribe, C. (2011).

La política que ellos llevan a cabo se distancia de los discursos convencionales y de las formas tradicionales de participar politicamente. El sólo hecho de salir a la calle es un gesto político y, trasmitir un mensaje a través de su obra lo hace doblemente político. No aspiran a cambiar el mundo por medio del arte urbano puesto que su aspiración política es diferente: controvertir las percepciones socialmente instituidas, cambiar la apariencia de la ciudad, incitar una reflexión, burlar las normas, cuestionar la situación presente, escandalizar. (p. 10-11).

\section{Arte y cultura o Ilegalidad y vandalismo}

Si definimos el arte como "el conjunto de disciplinas que se orientan a una finalidad expresiva y estética" (recuperado de http://www.definicionabc.com/general/arte. php), el Movimiento del Graffiti caza perfectamente dentro de la definición de arte, explícitamente dicho a la imagen.

Realizar un graffiti es una tarea que requiere un proceso de desarrollo muy complejo, pues quienes lo hacen están sujetos a ciertas condiciones que procuran alejarlo del fin (fig 3). Desde estructurar y llevar una idea clara de lo que se quiere plasmar, hasta determinar el medio urbano, junto al esfuerzo y la persistencia que la acción conlleva, son los limitantes que debe acoger y superar un artista del graffiti para ver su obra finalizada. 


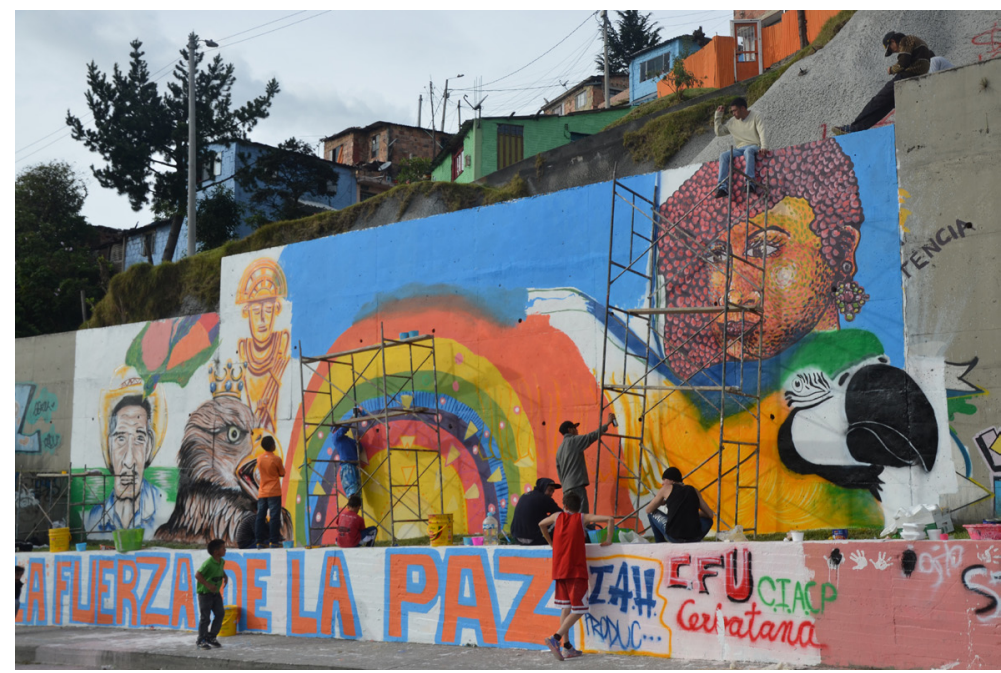

Figura 3. Grupo de jóvenes que dedican su tiempo a representar con sus imágenes "lo ambiental, lo ancestral, lo cultural y la diversidad ante todo" palabras del líder alias: Emigrante. Cerros orientales.

(fotografía del autor).

Para algunos, darles el nombre de "artistas", les da un carácter muy importante que para los académicos y artistas plásticos no es de su total agrado, pues dicen que para llevar ese nombres se debe pasar por un proceso de formación que muchos de estos jóvenes no conocen, y que es justo por esa razón que algunas imágenes chocan visualmente con la idea de ciudad. Para ser más preciso, según los puristas, solo los verdaderos artistas debería pintar las paredes de las calles, quienes lo hacen de forma ilegal, no son más que jóvenes dispersos y desadaptados que quieren expresar "porque sí" un algo sin concepto y sin sentido.

Estos jóvenes y su influencia sobre la población que cotidianamente los observa es muy importante en la opinión del artista callejero. Es importante resaltar que este movimiento artístico (que sí lo es), indudablemente acarrea para ellos represalias por parte de las autoridades competentes que trabajan para salvaguardar un orden social, sumadas a la de muchos ciudadanos, debido a que lastimosamente la actividad se encuentra asociada al tema de la ilegalidad y del vandalismo, además del estigma por estar vinculado con las clases sociales más bajas. Es por ello que quienes lo hacen, deben someterse al rechazo de las autoridades y la sociedad, y siempre seguir en procura de pintar sus ideas sobre los muros del espacio público.

\subsection{Perspectiva social}

"Se expresan a través del graffiti, aquellos mensajes que no es posible incluir en otros circuitos de comunicación, por incapacidad de poseer un medio". Umberto Eco 
El arte urbano procura una expresión artística, que a diferencia del graffiti, se considera como un acto vandálico y sin ningún fin. Como lo menciona el Docente Armando Silva, Ph.D, (Silva, 2014) "el graffiti, es una marca urbana relacionada con lo prohibido". A su vez plantea unos valores que determinan qué es y qué no un graffiti, características como la marginalidad, el anonimato y la espontaneidad, son las que definen el concepto en general.

Añade el profesor (Silva, 2014), "Para ser considerado graffiti, debe violentar un orden lingüístico, estético o político. Irrumpir en contra de lo que está establecido". Esto nos indica que el graffiti como tal no pide permiso, solo surge y se toma los muros y las calles (fig 4).

Al faltar alguna de estas características propias del graffiti, se entra en otro tipo de valoraciones que apartan por mucho su base ideológica. Por ejemplo, si un graffitero pide permiso a la ciudad para ejecutar su obra, excede la marginalidad, por tanto, carece de la condición intrínseca del graffiti, y pasaría a ser otro tipo de producción urbana que se cataloga como "Arte Urbano".

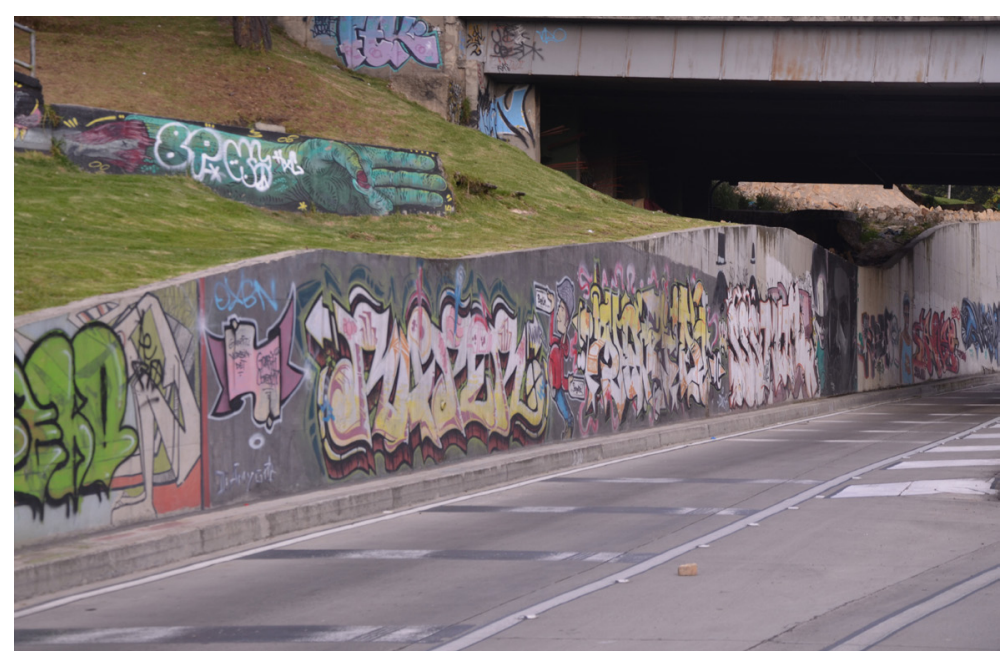

Figura 4. La particularidad del graffiti y su clandestinidad. Desbordan la ciudad con sus frases llenas de ironía y sátira. (fotografía del autor).

Por otra parte, se puede relacionar la importancia del graffiti con la necesidad de sus ciudadanos de expresar ideologías propias, que pueden caracterizarse dentro del ámbito social, político o simplemente, un pensamiento de opinión o emoción cotidiana. Por tanto es válido decir que el graffiti es parte de la identidad urbana, pues es considerado como un acontecimiento cultural que expresa lo concerniente a la misma sociedad, siguiendo una estructura artística.

Armando Silva afirma (Silva, 2014) "así como hay una necesidad de que existan canales de expresión en los medios de comunicación, también hay necesidad del graffiti". Los medios de comunicación procuran divulgar o comunicar aspectos de la sociedad, situaciones y acontecimientos dentro de la misma, pero ligados a una "restricción comunicativa" que impide en muchas ocasiones se exprese lo que realmente acontece. 
La información y mensajes que allí se presentan, por ende debe aprobarse previo a su divulgación, sin embargo, la necesidad no se satisface porque se le dé permiso, y ese es finalmente el papel del graffiti dentro de una comunidad, expresar y/o comunicar lo que no se dice; se satisface si y solo si hay personas, colectivos y/o grupos que utilizan esta opción para dar a conocer una postura, una opinión, o simplemente una crítica a lo que perciben de la sociedad a la que pertenecen.

Sin embargo, aunque el graffiti sea necesario para satisfacer dicha carencia de opinión no atendida; no significa que tenga que ser permitido. Como cita el profesor Armando Silva (Silva, 2014) "el graffiti es necesario precisamente en la no permisividad que tiene", a diferencia del arte urbano que, como se mencionó anteriormente, es permitido por su contenido más artístico que crítico, en pro de no ofender o deslegitimizar un movimiento, una campaña, o simplemente una problemática social a la cual no se preste mucha atención.

(Rodríguez, C. 2011). "La ciudad se ha convertido en el espacio por excelencia de representación y expresión de las nuevas tensiones sociales, culturales, y políticas".

\subsection{Análisis antropológico}

Dentro del campo social, caracterizamos la antropología del hombre como "cultural o etnológica", y desde el punto de vista del leguaje como medio de comunicación entre los individuos, caracterizamos la antropología del hombre como "lingüística".

Estas dos ramas de la antropología son las precisas para evaluar y dar una explicación poco más detallada y centrada con respecto a la manifestación artística del graffiti.

El hombre ha tenido la necesidad de comunicar lo que piensa o siente, y a través del tiempo ha encontrado diversas maneras de expresar todo aquello que le aqueja o alegra. Sin embargo la sociedad en su constante y exponencial evolución, ha impuesto muchos limitantes al hombre mismo para expresar su libre pensar. Así mismo surge una rebeldía o disociación entre ciertos grupos.

El graffiti surge de la necesidad de varios grupos de personas, de expresar un sentimiento de desacuerdo ante las normas, estatutos, y demás situaciones que a diario acontecen. Por tal motivo, aun siendo una expresión artística, es bien vista por unos, y rechazada por otros, haciéndola un medio de comunicación ligada a la subjetividad del público que la aprecie.

Un ejemplo remitido a dos sujetos de clases sociales (alta y baja). Siendo ellos dos espectadores potenciales de un graffiti plasmado sobre un muro de la ciudad, y con la aclaración de que ninguno de los dos es artista o conoce acerca de este movimiento, se detienen a observar el mismo graffiti. Tres cosas pueden pasar. Uno, que a ambos les agrade la obra, entiendan o no su significado; dos, que solo a uno de los dos guste la obra y al otro no, entiendan su significado o no; o tres, que a ninguno le agrade la obra y sigan su camino sin verse afectados por la misma.

Las tres opciones son completamente loables, pero lo que sí es claro es que la opinión de los espectadores siempre estará sujeta a la subjetividad. Ahora bien, si extendemos un poco el caso, en cuanto a lo que piensen ambos espectadores sobre la ubicación de la obra en la ciudad; puede ocurrir que al sujeto de una clase social más alta, le disguste la ubicación del graffiti o arte urbano pues ensucia la fachada de su 
calle y puede estar echándose a perder el aspecto de su ciudad, pero aun así disfruta de la imagen que ve directamente en la obra; mientras que al individuo de clase social más baja, le gusta en su totalidad la obra, su apreciación ante ella es porque hay una identificación con ella y ve que su calle se adorna con tan llamativos colores; esto demuestra la subjetividad en cuanto a su aprobación social. Va en el gusto de cada uno y cualquiera de las dos observaciones tiene total validez.

A veces no es la imagen lo que desagrada al público, sino la ubicación de estos en la ciudad, por lo que se inunda la mente con un inmediato pensamiento de rechazo, pudiendo ser una representación legitima de arte.

\subsection{Arte callejero - graffiti}

El arte callejero no se aleja de ese pensamiento social, sólo en Bogotá se ha destinado un espacio dónde los artistas han hecho de la ciudad un gran lienzo en el que logran estampar allí su pensamiento. Aunque se ha evolucionado en dicha apreciación y valor estético y visual, aún existen sectores de la sociedad que ven en este tipo de arte y tipo de manifestación suburbana algo de aquellos que se escudan en esto para cometer fechorías. Desde hace aproximadamente un par de años un grupo de jóvenes comenzó a tomarse con esta estética el centro de la ciudad, logrando así cambiar el paisaje urbano (fig 5). No se puede negar la gran majestuosidad con la que estos jóvenes transforman el espacio; colores, formas, anatomías, le han dado un gusto exquisito y de recorrido obligado.

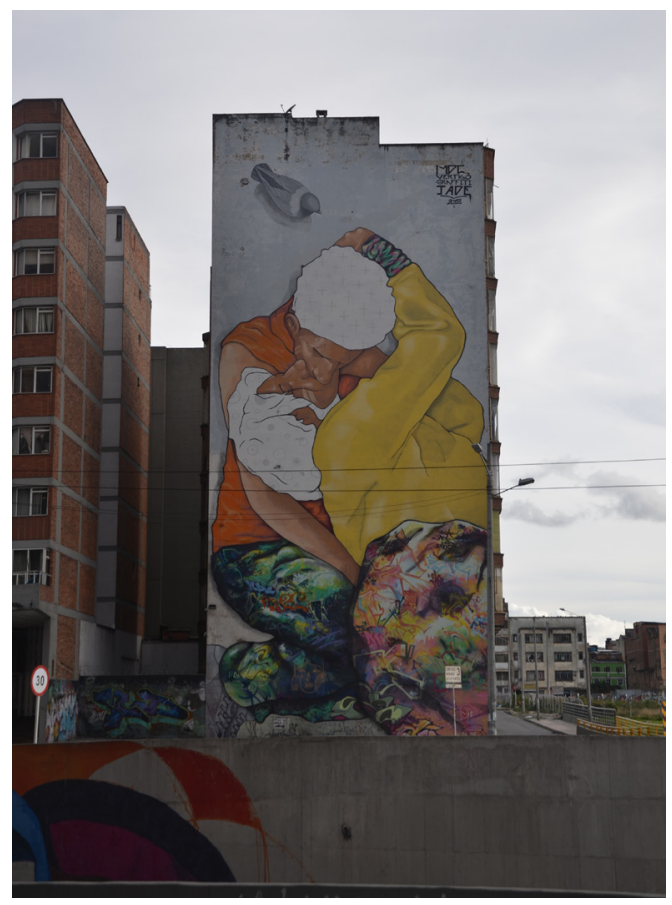

Figura 5. Obra de colectivo Vertigo Graffiti. Costado de edificio Clle 26 con avenida Caracas. Gusto o no, adorna la ciudad y le da un aire especial a esta zona deprimente de la ciudad. (fotografía del autor). 
De estos hechos sobre el concepto de Street art, Bogotá ha modificado su paisaje. El centro de la ciudad ha pasado de ser un mero espacio sórdido y sombrío, de recorridos peligrosos y visiones espectrales a un poderoso medio para expresar, plasmar y hacer sentir una idea que puede bien ser un reclamo, una queja, una burla, un mensaje político o simplemente la intención de difundir amor para quienes lo vean y lo disfruten como aquello sublime en una ciudad que como las grandes ciudades se sumerge en el caos.

La idea de estos artistas es tomarse las calles, apropiarse de un lugar y dar a conocer una idea, un dibujo con algo que deje y genere un impacto. Si quieren salir a hacerlo simplemente lo hacen pero la idea es tomar las calles con su propio lenguaje y expresar su propia sentir. Walls E. cita (2009)

Plasmar una idea en la pared de manera escrita quiere principalmente expresar la existencia de quien lo escribe y a si mismo mostrar que el problema al igual que todos también existe, "quiero decir que también existo. Yo existo! estoy aqui! Vivo!”. (p 37).

Para otros el Street art se ha convertido en un allanamiento, una especie de vandalismo de invasión del espacio público que por sus imágenes lo que más se genera es violencia.

La motivación hacia este movimiento nace del desarrollo de la investigación que busca netamente una posición reflexiva dado el problema que se presenta en la ciudad de Bogotá respecto a las diversas posiciones que lo defienden y los detractores que lo juzgan y criminalizan. Lo más difícil fue buscar los artistas o colectivos dispuestos a mostrar sus caras y ofrecer una entrevista. Pero se dieron finalmente las entrevistas con voceros que se encuentran en ambas partes del "conflicto", y se desarrolló un análisis exhaustivo de datos y legislación que acredita los espacios en los cuales se puede ejecutar el graffiti libremente en la ciudad, además de las iniciativas gubernamentales que fomentan la elaboración de graffitis en la ciudad. Para Peredo, P. (2009) "la presencia del graffiti en los espacios urbanos de la actualidad, puede considerarse que fundamenta el rechazo y la preocupación en la percepción de sectores mayoritarios de las sociedades que con el viven o conviven en la cotidianidad".

Entonces viene la pregunta ¿se valida o no el Street art por añadirle a la ciudad un aspecto más bello y el graffiti sigue siendo ilegal por ser vandálico y suponer en su escritura una motivación a lo irreverente, grosero e irrespetuso?. Viene entonces lo que el gobierno local bajo ciertas normas ha establecido.

\section{El ordenamiento territorial}

En su Carta Política el gobierno establece que "es deber del Estado velar por la protección de la integridad del espacio público y por su destinación al uso común, el cual prevalece sobre el interés particular" (artículo 71 de la Constitución Política de 1991). De acuerdo con este decreto, se diría que lo que los artistas callejeros hacen en las paredes va en contra de todo principio y derecho de la comunidad, pero realmente quien dice que ¿lo que hacen estos jóvenes artistas o colectivos está violentando ese espacio?. El recurso visual al que se le ha abierto la oportunidad de cambiar la ciudad 
por una simple pared a una obra de arte ha sido la opción de quienes prefieren darle un toque estético a lo cotidiano de la calle. En este contexto Olivares, R. (1997) dice:

La relación entre arte y ciudad es muy difícil de definir, porque el artista, quiere invadir un espacio público que nos pertenece a todos. Yo creo que quien tiene que intervenir en la ciudad es el arquitecto y el urbanista. El trabajo del artista no es solamente crear objetos bellos, eso es lo que hace un artesano, su trabajo es problematizar ciertos aspectos e ideas de su tiempo, crear un sentido y crear duda.

El espacio público nos pertenece a todos, es cierto, por eso es público. Pero también es justo decir que por ser público es deber de todo ciudadano cuidarlo, ¿a quién no le gusta cuidar su casa?. Es asumir ese espacio público como una propiedad, pertenece a la comunidad y como tal su cuidado es de todos, por eso viabilizar de manera discreta el uso de ese espacio para darle un aspecto más amable lo hace parte de un interés particular.

Por su parte el gobierno local ha establecido en su Plan de Ordenamiento Territorial (POT), lugares autorizados y no autorizados para la práctica del graffiti, con estrategias pedagógicas para la producción que promuevan y respeten principios y valores de la sociedad. Así dice la carta (2013):

a) Grafiti: Toda forma de expresión artística y cultural temporal urbana, entre las que se encuentran las inscripciones, dibujos, manchas, ilustraciones, rayados o técnicas similares que se realicen en el espacio público de la ciudad, siempre que no contenga mensajes comerciales, ni alusión alguna a marca, logo, producto o servicio.

b) Autor: Persona, natural o jurídica, o colectivo que concibe y realiza un graffiti.

c) Espacio público: Conjunto de inmuebles públicos y los elementos arquitectónicos y naturales de los inmuebles privados, destinados por su naturaleza, por su uso o afectación, a la satisfacción de necesidades urbanas colectivas que transcienden, por tanto, los límites de los intereses individuales de los habitantes.

d) Bien de Interés Cultural: Son bienes de interés cultural aquellos declarados como tales por las autoridades competentes, en razón del interés especial que el bien reviste para la comunidad. (POT, Plan de Ordenamiento Territorial, Alcadía Mayor de Bogotá. 2013, p 48).

El gran problema con las autoridades y el POT, ha sido que la practica del graffiti y obras de arte han invadido espacios no autorizados. Algunos de ellos, como el pavimento permitido solo para el tránsito de carros y peatones, espacios del sistema de transporte masivo y los mismos carros, ciclo-rutas, hasta el punto de utilizar las señales de tránsito y cubrirlas, semáforos, canecas de basura, servicios sanitarios públicos, bancas de los parques, kioscos de vendedores ambulantes, paredes de servicios de salud, escuelas y cementerios. Y lo que más le duele a los ciudadanos; en los elementos que estructuran la ciudad de forma ecológica como son los santuarios de flora y fauna, árboles de la ciudad, sedes culturales y monumentos históricos. El artículo 8 del POT dice al respecto:

Autorización de la Práctica del Graffiti en un inmueble Privado. Para el caso en que se pretenda realizar un graffiti en elemento arquitectónico o natural de un inmueble privado que haga parte del espacio público, se deberá contar con permiso previo y escrito del propietario del inmueble. (www.sdp.gov.co).

Asunto que no sucede, pues en conclusión el uso del espacio público para los graffiteros sí ha sido un acto vandálico de abuso permanente, al que no se puede ser 
ajeno. No se puede negar el gran valor artístico y visual que la ciudad ha ganado en la última década pero tampoco se puede negar el gran valor histórico con el que cuenta la ciudad y cómo se ve vulnerado por este tipo de actos, que a lo único que han llevado es a un enfrentamiento entre artistas, sociedad y autoridad. Y lo que es peor, hasta llegar a actos criminales que se evidencian en casos de homicidios y abusos en su mayoría por parte de las autoridades. Es el caso del joven graffitero muerto a manos de un policía que argumentó que el joven estaba implicado en un caso de atraco a un bus de servicio público y que en la huida debió dispararle. El caso cumple ya tres años y las autoridades no han aclarado lo sucedido. El policía está detenido, pero el proceso no ha prescrito.

\subsection{Aspectos generales de la ley}

La presente iniciativa tiene como finalidad regular la actividad de realizar graffitis en Bogotá, en razón a que esta actividad ha generado un conflicto entre los derechos de los ciudadanos: el derecho de expresión de quienes los realizan por llamarlo graffiti social y el derecho a un ambiente sano y al respeto del espacio público, de quienes consideran que su realización afecta el paisaje. Sobre el graffiti social como lo han llamado algunos teóricos Ramirez, M., Garcia, N. (2009) dice:

Graffiti social: necesidad de apropiarse de un espacio propio, debido a la imposibilidad material de utilizar otros cauces de comunicación o, en muchos casos, como una actividad planificada de llenar todos los espacios posibles para mostrar su opinión ante un determinado hecho. (p.305).

Sin duda, Bogotá es una de las ciudades más multiculturales de Colombia. Allí se concentran personas de diversas culturas, razas, religiones, condiciones sociales, etc.; y esto se expresa a través de diversas manifestaciones. Es así, que para muchas personas, los graffitis y obras callejeras son considerados "como una manifestación cultural, social y comunicativa que está presente y se involucra de manera activa en el ambiente metropolitano. Por eso, es una necesidad de indagar sobre su presencia y su función como elemento que expone una idea, una imagen y una concepción de mundo". Es por esto que actualmente Bogotá es centro de estudio y creación de diversos espacios artísticos urbanos a nivel nacional e internacional. De hecho, artistas, editores, curadores y realizadores audiovisuales se han acercado a ésta ciudad con un interés particular en la riqueza cultural y artística. No obstante, también para muchos, los graffitis son vistos como expresión que contribuye a la contaminación visual, convirtiéndose en un problema social que genera molestia a un sector de la población, pues además de incidir en la imagen urbana, genera gastos a los dueños para el mantenimiento de sus inmuebles, quienes más se demoran en sustituir estas imágenes por fachadas planas y con un color adecuado a la ciudad que estos artistas en volverlas a convertir en su lienzo callejero.

En algunos países, como es el caso de Argentina, Chile, México, e Inglaterra, los graffitis constituyen un problema grave para los gobiernos municipales, pues deben invertir grandes recursos para mantener y limpiar las paredes de la ciudad. 
El Gobierno Distrital, en colaboración con las Alcaldías Locales, ha tratado de fomentar espacios que sean útiles para la práctica del graffiti en los jóvenes, cómo expresión propia de la cultura hip-hop, al igual que a los murales artísticos sin patrocinio, ya que son catalogados como obras de arte. Por eso, ha dispuesto de construcciones que son propiedad de la municipalidad para que sean pintadas por jóvenes (fig 6). Es así como en algunas partes de Bogotá se puede ver la calidad y los amplios espacios que son utilizados por los jóvenes para construir sus murales.

Por esto la estética de la ciudad se ve obligada a cambiar de aspecto, una estética fluctuante dominada por la temática del artista de paso, que añade al espacio cotidiano una belleza particular que cambia el aspecto rudo y dolorosos de una ciudad que sobrevive al absurdo. Estética de lo feo o lo bello, no deja de ser diferente. Para Jan Mukarovsky (1975).

Se asume lo estético como una cualidad expresiva, lo restringido sólo a la obra de arte, cualquier acción o cualquier acto del hombre, son susceptibles de ser asumidos desde una postura estética, porque en ellos se vehicula toda la sobrecarga simbólica que configuran el ser y el hacer del hombre contemporáneo en la cultura, que articulan lo cotidiano dentro de una categoría antropológica de contrastes e interacciones. (p. 47).

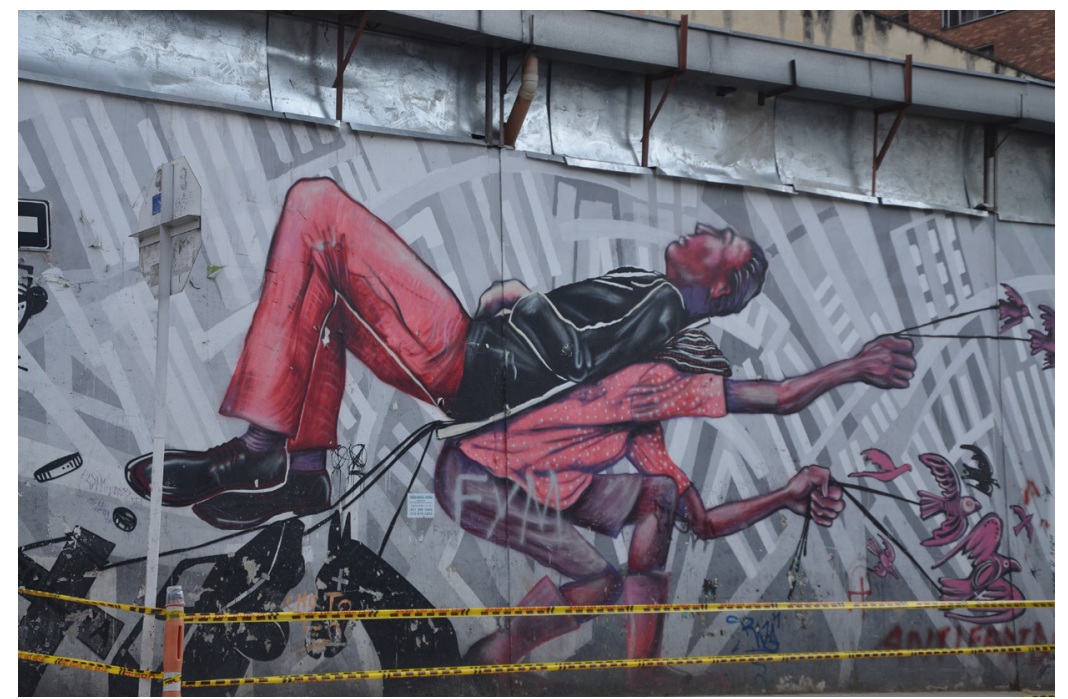

Figura 6. Obra de arte representada por un colectivo de artistas callejeros con el aval de las autoridades municipales. (fotografía del autor).

No obstante, no ha sido posible incentivar y estimular organizadamente el uso de graffitis en estos sitios o lugares específicos, sino que por el contario, se han desviado éstas manifestaciones culturales a fachadas, puertas, ventanas, mobiliario público, etc. Según Armando Silva "el uso social de un espacio marca los bordes dentro de los cuales los usuarios "familiarizados se autorreconocen" " y el arte público es clave en este proceso, en el sentido en que la creación contemporánea nos invita a cambiar nuestros modos de ver, para descubrir una nueva propuesta, lo que Gustavo Zalamea (Zalamea, 2000) llama, "una especie de acontecimiento primordial". 
Con el presente proyecto no se pretende hacer una crítica sobre la libertad de expresión, ni ningún tipo de manifestación cultural o artística, por el contrario, se busca promover espacios específicos para la libertad de expresión, pero respetando y garantizando los derechos sobre los bienes públicos y privados.

En mayo del año 2010, el Periódico El tiempo expresó cómo los graffiteros, están atentando las estructuras de TransMilenio (transporte público urbano). Así mismo, señaló:

"De los 64 puentes peatonales que existen en el sistema TransMilenio, más de la mitad se encuentran deteriorados por culpa de vándalos que los pintan o se roban las láminas para comercializarlas en el mercado negro" (El Tiempo, mayo 2010).

Todo tiene un limite, ese limite se ha sobrepasado, el uso se ha pasado hacia un abuso de propiedad, y por más permisividad es importante que se respete el espacio público para estos casos y se generen pedagogías hacia el cambio.

\section{Conclusiones}

Es importante destacar la labor de los jóvenes colectivos de artistas callejeros que han aportado a la ciudad un cambio en su estética. La paredes que hablan, los retratos de una ciudad en conflicto y su necesidad de salir de lo convencional develan la necesidad de cambios sustanciales.

Los graffiteros desde la década de los 80 comenzaron a condicionar la ciudad de Bogotá en su recorrido, los ciudadanos comenzaron a ver con buenos ojos este tipo de estética, pero con el paso de los años estos mismos graffiteros fueron vulnerando los espacios públicos obligando a la gente a ver en sus anuncios declaraciones que no todos compartían.

Se abren entonces espacios de participación para artistas callejeros que llevados por una especie de sublevación y queriendo salir de la marginalidad, comienzan a proyectar sus imágenes en las calles de la ciudad. Son espacios que las mismas autoridades han destinado para este trabajo, pero lamentablemente se sigue vulnerando el bien privado y público, la casa, la tienda, el almacén, la escuela. No se puede negar que algunas calles de la ciudad en su gran flujo vehicular se han convertido en un paso mucho más amable y confortable por lo adornada que se ve, pero también se debe tener conciencia de esos espacios, y respetar el bien privado. En una sociedad donde por más de medio siglo se ha vivido bajo el caos, el abuso, la violencia, el conflicto, la agresión y hasta el desplazamiento, no se puede abusar más de esto. La tolerancia hasta estos espacios se ha colapsado y entones se enfrentan autoridades, civiles y artistas en un interminable proceso que no encuentra salida.

El artista callejero, el graffitero, debe seguir en su marginalidad, en la invasión del espacio sin permiso, porque finalmente esto es lo que lo hace real, esto es lo verdadero; el temor de la noche, el camuflaje, correr, huir es lo que hace de este tipo de expresión artística un verdadero manifiesto. "Yo creo que todavía no es demasiado tarde para construir una utopía que nos permita compartir la tierra." (García M. G. 1962). 


\section{Agradecimientos}

A la Universidad Militar Nueva Granada, por su financiación en el proyecto de investigación INV. ING-1813, titulado "Resignificación de Street art o (in) cultura ciudadana. Bogotá un gran lienzo para la anamorfosis."

\section{Referencias}

Berger, J. (2002) Modos de ver. Barcelona. Ed. Gustavo Gilli Bou, L. (2010) Barcelona Street Art. Barcelona. IJB Ediciones.

Candia, P. Rodriguez, A. (2011). Graffiti como manifestación de disidencia en América Latina. Universidad Iberoamericana.

Castro, S., Vásquez, R., Fajardo, E., Mojica, S., Arbeláez, V., García, S. (2012). Diagnóstico Graffiti Bogotá 2012. Graffiti Bogotá 2012.

García, M.G. (1962). "La mala hora".

Mukarovsky, J. (1975) Escritos de estética y semiótica. España: Gustavo Gili, p. 47. Olivares, R. (1997) El artista y la ciudad: Una utopía. Festival internacional de arte. Medellín.

Peredo, P. (2009). El Graffiti: su evolución y percepción social a favor o detrimento de una ciudad. Topofilia. Revista de Arquitectura, Urbanismo y Ciencias Sociales.

Castro, S. (2012). Diagnóstico Graffiti Bogotá 2012. Graffiti Bogotá 2012. PDF. p. 25.

Silva, A. (2014). Atmosferas Ciudadanas, graffiti, arte urbano nichos estéticos. Bogota: Universidad Externado de Colombia.

Uribe, C. (2011). El arte urbano y la producción de sentidos políticos juveniles. VI Jornadas de Jóvenes Investigadores. Instituto de Investigaciones Gino Germani.

Vega, B. (2012). Lenguaje visual publicitario como sistema de comunicación en el Street Art: creación y difusión. Universidad Autónoma de Barcelona.

Walls, E. (2009). Graffiti, Hip-Hop, Rap, Breakdance. Las nuevas expresiones artisticas.

Zalamea, G. (2000) Arte y Ciudad. Problemas y sugestiones. En: La Ciudad: Hábitat de diversidad y complejidad. Universidad Nacional de Colombia. Santafé de Bogotá. p. 163. 